\title{
UNDERSTANDING THE DYNAMIC OF TROPICAL AGRICULTURE FOR REMOTE SENSING APPLICATIONS: A CASE STUDY OF SOUTHEASTERN BRAZIL
}

\author{
I. D. Sanches ${ }^{1 *}$, A. J. B. Luiz $^{2}$, B. Montibeller ${ }^{3}$, B. Schultz ${ }^{4}$, K. Trabaquini ${ }^{5}$ I. D. R. Eberhardt ${ }^{6}$, A. R. Formaggio ${ }^{1}$, L.E. Maurano ${ }^{1}$
${ }^{1}$ National Institute for Space Research (INPE), Av. dos Astronautas, 1758, Jd da Granja, 12227-010, São José dos Campos, SP, Brazil - ieda.sanches@inpe.br; formag@dsr.inpe.br; luis.maurano@inpe.br
${ }^{2}$ EMBRAPA, Rodovia SP-340, Km 127,5, 13820-000, Jaguariúna, SP, Brazil - alfredo.luiz@embrapa.br
${ }^{3}$ Department of Geography, University of Tartu, Vanemuise 46, 51003, Tartu, Estonia - bruno.montibeller@ut.ee
${ }^{4}$ Geoambiente Sensoriamento Remoto, Parque Tecnológico UNIVAP - Av. Shishima Hifumi, 2911, Urbanova, $12244-000$ - São
José dos Campos, SP, Brazil - bruno.schultz@geoambiente.com.br
${ }^{5}$ EPAGRI/CIRAM, Rodovia Admar Gonzaga, 1.347, Itacorubi, Caixa Postal 502, 88034-901,
Florianópolis, SC, Brazil - klebertrabaquini@epagri.sc.gov.br Campus Universitário, Brasília, Brazil - isaquedanielre@hotmail.com \\ ${ }^{6}$ Civil and Environmental Engineering Department Transportation Program - PPGT, University of Brasília - UnB, Darcy Ribeiro,
}

\section{Commission III, WG III/10}

KEY WORDS: Satellite image, Optical sensor, Multispectral, RGB false composition, NDVI, Monitoring

\begin{abstract}
:
The agricultural activity can greatly benefit from remote sensing technology (RS). Optical passive RS has been vastly explored for agricultural mapping and monitoring, in despite of cloud cover issue. This is observed even in the tropics, where frequency of clouds is very high. However, more studies are needed to better understand the high dynamism of tropical agriculture and its impact on the use of passive RS. In tropical countries, such as in Brazil, the use of current agricultural technologies, associated with favourable climate, allow the planting period to be wide and to have plants of varying phenological cycles. In this context, the main objective of the current study is to better understand the dynamics of a selected area in Southeast of São Paulo state, and its impact on the use of orbital passive RS. For that purpose, data (from field and satellite) from 55 agricultural fields, including annual, semi-perennial and perennial crops and silviculture, were acquired between July 2014 and December 2016. Field campaigns were conducted in a monthly base to gather information about the condition of the crops along their development (data available in a website). Field data corresponding to the 2014-2015 crop year were associated with a time series of Landsat-8/OLI RGB false-colour compositions images and MODIS/Terra NDVI profiles. The type of information that can be extracted (such as specie identification, crop management practices adopted, date of harvest, type o production system used etc) by combining passive remote sensing data with field data is discussed in the paper.
\end{abstract}

\section{INTRODUCTION}

Although cloud cover represents a major hindrance (Whitcraft et al., 2015), data from orbital optical passive sensors are worldwide applied to monitor agriculture areas. The cloud issue is even more relevant for the use of passive remote sensing in the tropics, due to the high frequency of clouds (Sano et al., 2007; Eberhardt et al., 2016). However, in these regions, there is another highly relevant point for the orbital remote sensing to be effectively able to assist the agricultural monitoring, that is the necessity to better understand the high dynamism of tropical agriculture and its impact on the use of remote sensing.

An example of highly dynamic agricultural country is Brazil. In the last three decades, the increase in Brazilian agricultural productivity was impressive. It was so significant that, at the same time, it was possible supply the needs of a growing population with increasing income, generate trade surplus that has allowed the improvement of others socio-economic indicators of the country, and contribute to environmental conservation by not expanding the cropped area in same proportion as production. Only for the three main crops produced in Brazil, sugarcane, soybean and maize, according to data the Brazilian Institute of Geography and Statistics (IBGE) the production increased $181 \%, 336 \%$, and $274 \%$, respectively, from 1990 to 2014, while areas grew $144 \%, 164 \%$, and $35 \%$ for the same crops and time. In addition to the quantitative growth, the location of agricultural production has changed a lot in this period. This dynamic is not common in another countries, especially that ones with important volumes of agricultural production. In addition, one way to monitor it, especially considering the size of Brazilian agricultural area, is using remote sensing technology.

When analysing satellite images, the spectral response of one crop can vary greatly in the same scene. This is especially true for tropical and subtropical regions where the agriculture has intense dynamism. In these areas, the use of current agricultural technologies (e.g. irrigation, no-tillage, minimum cultivation, early varieties, desiccants, flowering inducing, growth regulator etc), associated with favourable climate, allow the planting

\footnotetext{
* Corresponding author
} 
period to be wide and to have plants of varying phenological cycles (Sanches et al., 2018a).

Considering the necessity of having better comprehension of the development of crops in satellite images, in dynamic areas, our research group selected a region in Southeast of São Paulo state, Brazil, to conduct a 30 months monitoring project. Apart from being representative of the agriculture found in São Paulo state, the study area chosen is located in a region imaged by two adjacent Landsat paths. This was intentionally done to improve the temporal resolution of Landsat images from 16 to 7-9 days, to increase the chances of acquiring cloud free images, and consequently to provide a better spectral characterization of crops development.

In this context, the objective of the current study is to better understand the dynamics of a selected area in an important Brazilian agricultural region, and its impact on the use of orbital passive RS. To accomplish that, this paper presents the results of a project, in which 55 agricultural targets (e.g. annual crops, semi-perennial crops, perennial crops, silviculture), in Campinas mesoregion, were visited monthly during two crop years (2014-2015 and 2015-2016). The data collected in the field during the 2014-2015 crop year were associated with a time series of Landsat-8/OLI RGB false-colour compositions images and MODIS/Terra NDVI profiles.

\section{MATERIAL AND METHODS}

\subsection{Study area}

The study area is located in the mesoregion of Campinas, in São Paulo state, Brazil (Figure 1). The agricultural production value of this mesoregion is considered above the state average, and is not based on just few activities, presenting an interesting and challenging diversity for testing the ability of agricultural monitoring by remote sensing. It presents significant areas of sugarcane, bean, sunflower, cassava, maize, soybean, wheat, citrus, rubber, eucalyptus and pasture.

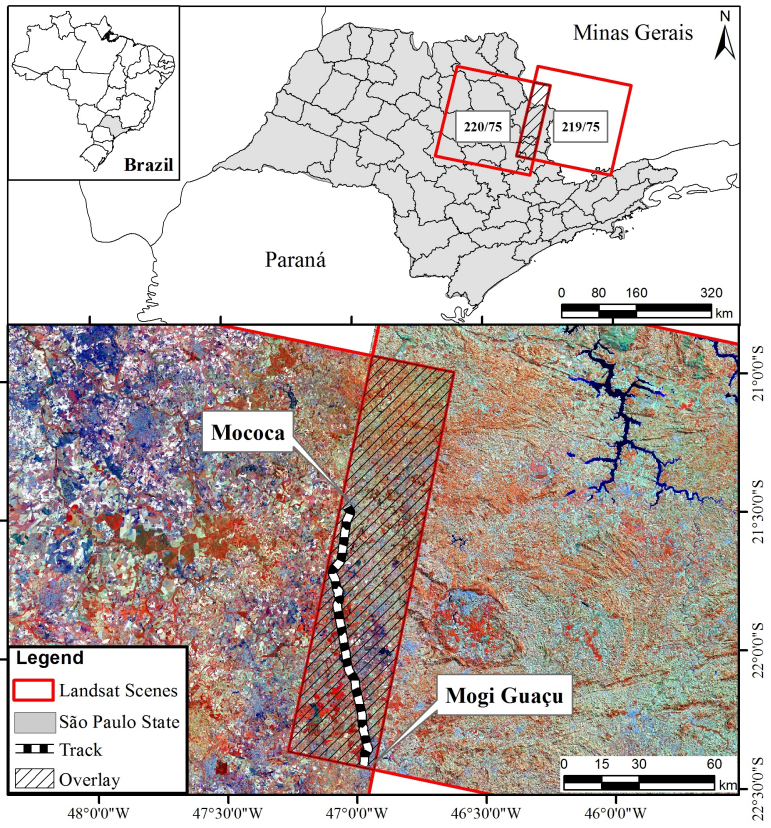

Figure 1. Study area. Map with the location of the field track (highlighted in black and white) visited monthly.
The study area is located in a spot of Brazilian Savanna. The soils predominant in this region are the Red Latosols, the Redyellow Latosols and the Red-yellow Ultisols); with slightly undulated relief (3-13\%). According to Koppen classification, the dominant climates are the Cwa, humid subtropical climate; and the Aw, tropical wet-dry climate.

Apart from be an important agricultural area, the mesoregion of Campinas was chosen because of its privileged localization, with roads in good conditions, crossing cultivation areas of important crops, allowing the identification of dozens of fields with different agricultural land use, in a course of a few hundred miles. Moreover, the specific region selected for the present study is located in an overlap area of two Landsat Worldwide Reference System-2 (WRS-2) scenes, corresponding to the $220 / 75$ and $219 / 75$ paths/row. The advantage is the temporal resolution of image acquisition can be doubled. For example, considering the OLI/Landsat-8 (temporal resolution of 16 days), it goes from traditional annual 23 possible images to 46 , which increases the probability of obtaining cloud free images.

Fifty-five sites of a variety of agricultural classes (e.g. annual crops, perennial crops, native forest, silviculture, pasture) were monitored, in a buffer zone of $2 \mathrm{~km}$ (for each side) along a track in the Highway SP-340, going through the municipalities of Mogi Guaçu, Estiva Gerbi, Aguaí, Casa Branca and Mococa, SP.

\subsection{Field and satellite data acquisition}

The field track (Mogi Guaçu to Mococa - MGM - round trip) was done monthly, between July 2014 and December 2016, to gather information about the condition of the 55 agricultural fields monitored, such as type of crop, plants phenological stage, periods of sowing, flowering and harvest, agricultural management practices adopted etc. Photographs were taken in each field plot (from the same spot), in each field campaign, to document the changes observed along the time of the monitoring.

For the period analysed, we acquired, from the USGS EROS Centre, all available OLI/Landsat- 8 images corresponding to the 219/75 and 220/75 paths/row (cloudy images were discarded). In addition, MODIS/Terra NDVI profiles corresponding to the monitored areas were acquired from the SatVeg platform (https://www.satveg.cnptia.embrapa.br/satveg/login.html).

According to the Brazilian National Food Supply Agency (Conab), the crop year goes from August to July, and the periodicity of Brazilian crops is: 1) first summer crop - August to May; 2) second summer crop - December to July; and 3) winter crop - April to December. These cropping windows are theoretical, because species can be cultivated with different growth cycles, which can change the duration of each window, but in generally, these, are the periods expected a priori.

\subsection{Data processing and analysis}

This study was divided in two parts. 1) Analysis of the data collected in the field, to understand the agricultural dynamics. 2) Association of field data and satellite data (time series of Landsat-8/OLI RGB false-colour compositions images and MODIS/Terra NDVI profiles) to analyse the potential and 
limitations of passive remote sensing data for monitoring agriculture in dynamic regions.

2.3.1 Field data: Based on the data collect in the monitored sites, at each field campaign, the following information were extracted: 1) types of crops cultivated in each season (summer and winter crops); 2) type of cropping used (single, double, triple); 3) crop rotation used; 4) time (month) of planting and harvesting; 5) duration of the crops phenological cycles (in months); 6) if the crops were artificially irrigated (e.g. by central pivot); and 7) management practices adopted (e.g. sugarcane burn, no-tillage). This information is available at http://www.obt.inpe.br/agricultural-database/mgm/.

2.3.2 Association of field and satellite data: For visual interpretation of the OLI images acquired, the RGB 564 (near infrared - NIR, shortwave infrared - SWIR, Red) colour composition was adopted. The use of this composition is traditional when working with agricultural targets because it highlights differences among distinct crops types (Formaggio and Sanches, 2017).

To improve visual interpretation, since we used a set of multitemporal images in this study, an equalization procedure was applied to the images to ensure that all compositions presented the same contrast. Thus, the visually observed colour or hue differences could be attributed to target characteristics (e.g. type of crop or phenological phase) and not to other variables related to image acquisition. The equalization procedure adopted in this study consists of an adaptation of the method developed by Schultz (2016). Instead of using one image as reference, as suggested by the author, better results were obtained when we used two images, one for the dry season (April to September) and other for the raining season (October to March).

After the equalization, the changes in the OLI images compositions and in the MODIS/NDVI profiles were visually analysed along with the photographs and information collect in the field.

\section{RESULTS}

\subsection{The 55 agricultural fields monitored in situ}

The area of the plots analysed varies between 8 and 400 hectares. Among the plots cultivated with annual crops, fourteen are irrigated by central pivot system and one by water cannon. The crops found in the monitored plots were bean; cassava; citrus; lychee; maize; mango; potato; sugarcane; soybean; sorghum; sunflower; oat; rubber and wheat. The silviculture corresponds to eucalyptus, pine, and teak tree. There are also remaining native forests, pastures and a hay field. Coffee is the only crop of economic importance in the São Paulo state that is not present in the studied region.

Crops rotation was a common practice observed among the monitored plots. Considering the crop year 2014-2015, maize and soybean were cultivated as first summer crops (August 2014 to April 2015); bean as second summer crop (February to March 2015) and maize, potato, sunflower, bean, wheat, sorghum, oat and cassava as winter crops (April to September 2015). The following rotation of two crops (double cropping system) occurred: maize-sunflower, maize-potato, maize-wheat, maize-bean, maize-maize, soybean-oat, soybean-potato, soybean-wheat, soybean-sorghum and soybean-cassava.
In some plots with early plantation of the first crop (seeded in August/September and harvested in December 2014), there was the rotation of three crops (triple cropping system): maize-beanwheat, maize-bean-maize. All irrigated areas presented double or triple cropping systems. There was double cropping even in non-irrigated areas. In some plots the same species was cultivated as second crop in 2013/2014 and 2014/2015, however, in others, a different second crop was planted in 2014/2015

Considering summer and winter crops cultivated in the agricultural plots selected, the collection of data over 16 months were necessary to cover the entire (from the sowing/planting to the harvest) $2014 / 2015$ crop year. In this period, maize was sown in five different months (August, September, November, April and May); soybean in two months (November and January); and bean in four months (August, February, May and July). All other crops (winter crops) were planted between April and July. Beyond the multiple planting dates, the phenological cycle of the crops has also varied. It was observed maize cycle of 4,5 or 6 months; soybean cycle of 3,4 and 5 months; sorghum and sunflower cycles of 5 months; oat cycle of 4 months; potato cycle of 3 or 4 months; bean cycle of 2 or 3 months; and wheat cycle of 3 months. Among the 16 months analysed, maize was found in the field in 14 months (August 2014 to September 2015); bean in 11 non-consecutive months (July to October 2014, February, March and May to September 2015); soybean in 6 months (November 2014 to April 2015); sunflower, potato (May to September) and sorghum (April to August) in 5 months; and wheat (May to August) and oat (June to September) in 4 months.

The period between November and March (summer crop season) has the greater intensity of agricultural land use, while the lower land use intensity occurs in September, October and April (months prior and after first crop season). The greater diversity of annual crops cultivated occurred in May, June and July, while the period between September and January presented the lower diversity. Thus, the agricultural year can be divided in three periods considering annual crops: i) November to March - high intensity of agricultural land use and low diversity of crops; ii) May to August - medium-high intensity of agricultural land use and high diversity of crops; iii) September, October and April - low intensity of agricultural land use and low diversity of crops.

According to the field data analysed, the sugarcane harvest occurred from May to July and in October 2015. Among the seven plots of sugarcane monitored, only one was not harvest in 2015; this plot was last harvested in August 2014. Two of the stands were burnt before harvest.

Cassava harvest occurred in January and October. The pastures oscillated their biomass content depending on the availability of rain. The hay plot monitored was constantly harvested, almost every month. Apart from flowering and fructification, no change was observed for the perennial crops (mango, citrus and lychee), with exception of rubber. Rubber trees are deciduous, in the plot analysed the trees were leafless on August.

The only dynamic observed in the native forest plots was the incidental burn of one of them. Eucalyptus and Pine did not present any expressive change during the period analysed. The teak trees, which is also a deciduous specie, lost their leaves from July to September. 


\subsection{Association of field and satellite data}

For some selected targets monitored, the time series of OLI images (clippings), MODIS/NDVI profile and the correspondent field photographs is presented in this paper (Figures 2 to 6). Although the time gap (in days) between image and photograph acquisition dates varied between 0 and 28, in the majority of the cases it was equal or less than 7 days. The larger time gaps, 28 and 21 days, were observed for March and November, respectively, when no cloud free OLI image were available for the study area.

For the visual analysis of the time series of OLI/Landsat-8, it is important to notice that, in the colour composition adopted (OLI RGB564), since vegetation highly absorbs the electromagnetic energy (EME) in the red part of the spectrum (OLI B4) and strongly reflects EME in the NIR (OLI B5), healthy green vegetation targets, i.e. photosynthetically active vegetation, (e.g. maize) appear in red colour (hues of red and brown). Although reflecting more in the NIR, some types of healthy green vegetation (e.g. soybean) also have high reflectance in the SWIR (OLI 6), and the combination of high reflectance in both NIR and SWIR make them appear in yellow colour (hues of yellow and orange) in the RGB654 images compositions (Formaggio and Sanches, 2017). These red and yellow colours in the images are to be expected when the plants are in full development (high green biomass). As the plants advance in their phenological cycles (e.g. flowering, senescence), their spectral response might assume other colours in the images, as will be discussed further in the text.

Also, in the OLI RGB564, the soils (found in the study area) appear in blue colour (high reflectance in OLI B4, Red spectrum) and straw of harvested vegetation appears in cyan (high reflectance in OLI B4 and B6, Red and SWIR, respectively) or white colours (reflects equality in OLI B4, B5 and B6). Therefore, a bare soil prepared to be cultivated will appear in blue colour. After been sowed or planted, a crop plot will look like a soil plot in the image (or a straw plot if the crop was cultivated under no-till farming), since the response of soil (or straw) will dominate the spectral behaviour observed in the images until the crops reach sufficient size to cover or minimize the soil background. Then, as the plants grow, the spectral behaviour will be gradually dominated by the vegetation response and will be less dominated by the soil (or straw) response.

3.2.1 Annual crops: An example of crop rotation of maize followed by soybean in an area irrigated by central pivot is presented in Figure 2.

In the MODIS/NDVI profile presented on Figure 2, it can be observed that two annual crops were cultivated in the plot, in sequence, between July 2014 and June 2015; and that they reached their maximum vegetative development (higher NDVI values) on October 2014 and March 2015. According to field data, the first crop was maize, which was sown in the beginning of August 2014.

In the OLI images (Figure 2), the spectral behaviour observed were dominated by the soil (appears in blue colour in the RGB564 composition) until the end of August. Only from September, this maize plot assumes the expected reddish colour in the OLI images. So only then, it could be confirmed, based on the image visual interpretation, that there was a crop growing in the plot. As there was no available cloud free image during November, the moment the maize starts the senescence process is missed in the OLI images. From December, this maize appears in the image in a dark green colour; this is consequence of the presence of several dry leaves, as can be observed in the photograph taken in 16/12/2014. On $10 / 01 / 2015$, the harvest begins, as indicated in the image by the line in the middle of the plot in cyan colour. On 17/01/2015, the plot was all harvest. The next available image was in $11 / 02 / 2015$, when the soybean was already showing the characteristic yellow colour. In $02 / 05 / 2015$, the cyan colour of the image indicates that the soybean was already harvested. In $10 / 06 / 2015$, the soil tillage for the next crop begins, as indicated in the image by the dark blue line in the middle of the plot.

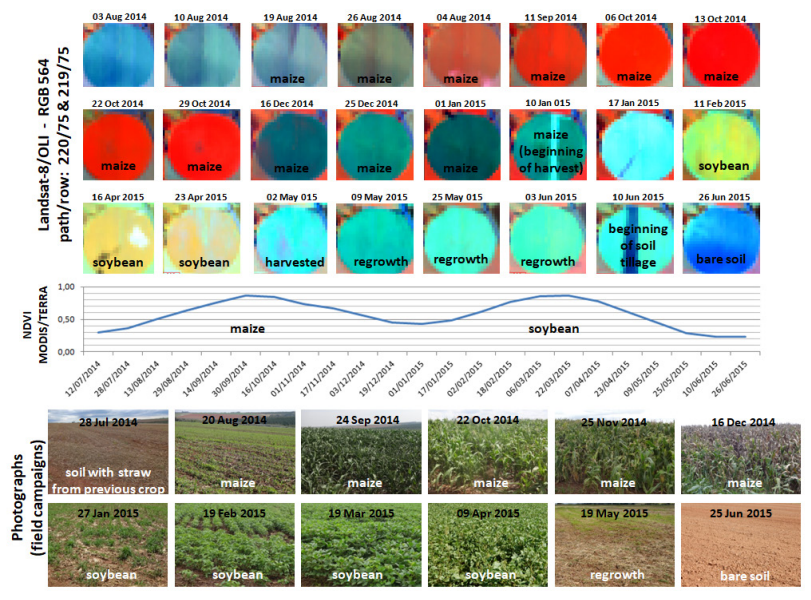

Figure 2. Field and satellite data of an area cultivated with crop rotation of maize followed by soybean. Source: Parts of the

figure was adapted from Formaggio and Sanches (2017).

3.2.2 Semi-perennial crops: Two semi-perennial crops were analysed in this study, sugarcane (Figure 3 ) and cassava (Figure 4).
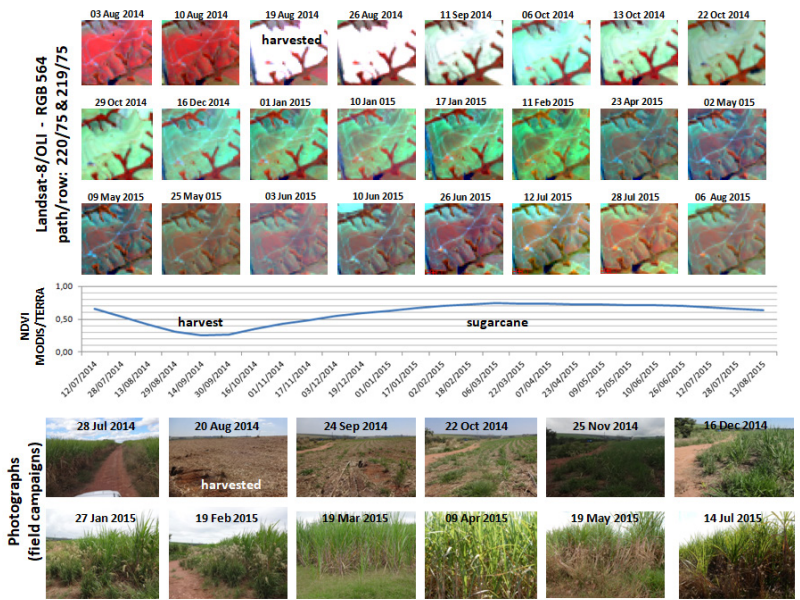

Figure 3. Field and satellite data of an area cultivated with sugarcane. Source: Parts of the figure was adapted from Formaggio and Sanches (2017).

Analysing the OLI images acquired and the MODIS/NDVI profile (Figure 3), the greatest change observed along the development of the sugarcane is caused by the harvest. The plot with the adult sugarcane appears in a red colour (03- 
$10 / 08 / 2015)$, and after the plant is harvested, it turns to white $(19 / 08 / 2015)$. The white colour is the typical response of sugarcane areas harvested mechanically, in which the dry straw is left in the field evenly spread throughout the soil. After been cut, the sugarcane starts to regrow, and gradually gain biomass. In the image acquired on $11 / 09 / 2014$, it is possible to observe the regrowth (the white colour turns to green). Because the planting space between sugarcane rows are large (1.0 to $1.8 \mathrm{~m})$, it takes few months for the plants to reach sufficient high to cover the soil. For that reason, the typical response of green vegetation (reddish colour in OLI RGB 564 composition) will be observed in the images only after few months have passed since the sugarcane harvest.

As all other crops, the early stages of cassava development cannot be detected in the satellite images because the canopy spectral response is dominated by the soil (Figure 4). After reaching full vegetative development, the cassava appears in yellow/orange colour in the OLI RGB564 composition. The cassava is a semi-perennial specie that loses its leaves during the plant development. This can be observed in the images acquired from the end of May onwards. In the photograph took in the field campaign done in $14 / 07 / 2015$, the cassava plants were almost leafless (also some weeds are observed in the plot). As a result, in this phase, the spectral response is dominated by the plants stalks (highly reflects in the SWIR) and the soil (highly reflect in the Red). This explain the spectral response observed in the OLI image from 12/07/2015, where the plot appears in cyan colour. In some parts of the plot analysed (e.g. bottom of the plot), the colour observed in the image is brownish (not cyan), which corresponds to the presence of weeds.
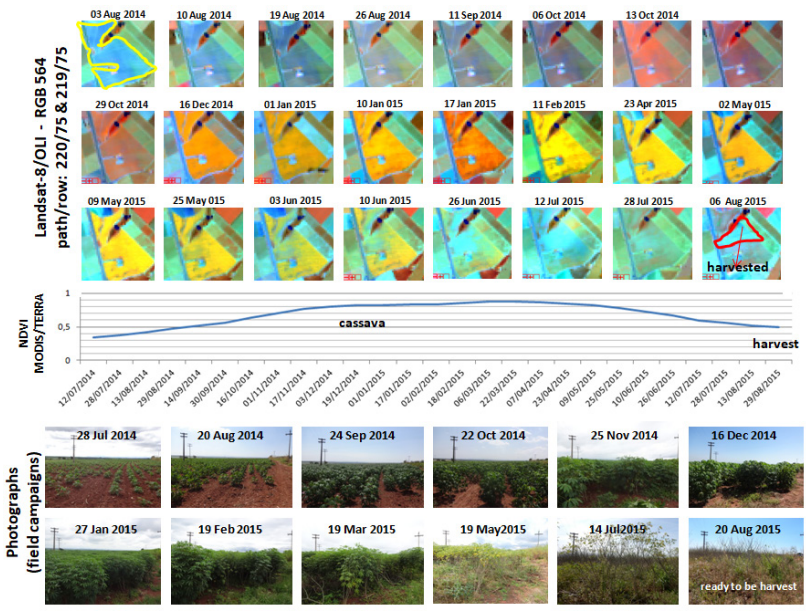

Figure 4. Field and satellite data of an area cultivated with cassava. Source: Parts of the figure was adapted from Formaggio and Sanches (2017).

3.2.3 Perennial crops: In this study, two perennial crops, rubber tree and citrus, are analysed based on their spectral response.

The rubber tree is a semi-perennial plant with deciduous habit. That means it loses it leaves periodically. In Figure 5, an example of rubber tree plot is showed. The leaf fall was observed from June to August months (lower NDVI values). This event is clear noticeable in the OLI images (change from brown/red to green colour). It is also perceptible a change in image colour, from red to brownish, from the 29/10/2014 image to the 16/12/2014 one. However, this alteration could not be correlated to any event or plant development phase. It is probably a seasonality issue of the images that was not handled by the equalization procedure adopted in this study, which needs to be further investigated. This was observed, although less evident, in other targets (e.g. citrus and teak tree).
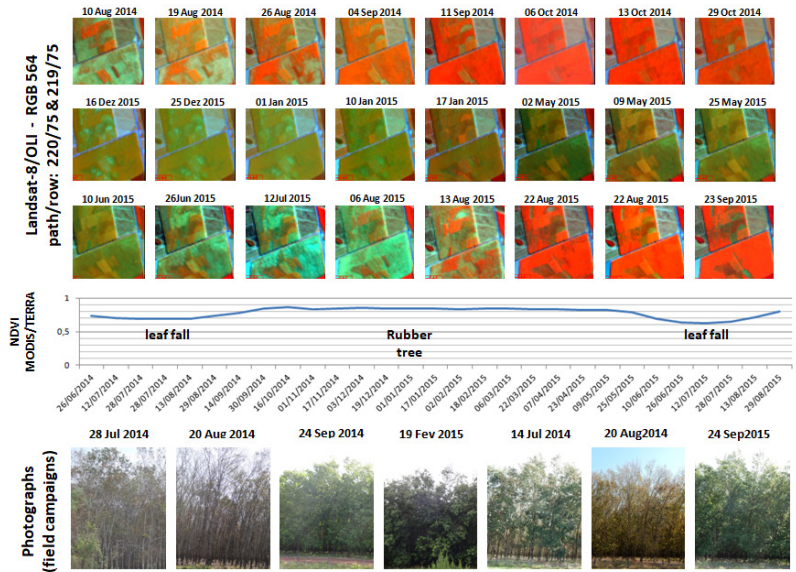

Figure 5. Field and satellite data of an area cultivated with rubber tree. Source: Parts of the figure was adapted from Formaggio and Sanches (2017).

Examining the temporal OLI images of a citrus area selected (not show), hardly any change is observed across the plot during August to October 2014. From the first image acquired on December (16/12/2014) until the middle of the next year, some variation is noticed. This is not related to any phase of plant development, but to agricultural management practice adopted. Because the citrus plants are cultivated with large space between planting rows $(6$ to $10 \mathrm{~m})$, the presence or absence of vegetation between rows has a great impact on the spectral response of the citrus canopy. In areas where there is high grass between rows, the brown colour prevails in the OLI RGB564 composition (response of green vegetation); while in areas where the vegetation between rows was removed (by mowing or application of agricultural desiccants), the green colour is observed (mixed response of green vegetation, dry vegetation and soil).

3.2.4 Silviculture: Among the species of planted forest found in the study area, Eucalyptus and Pine did not presented any change in spectral behaviour during the time analysed.
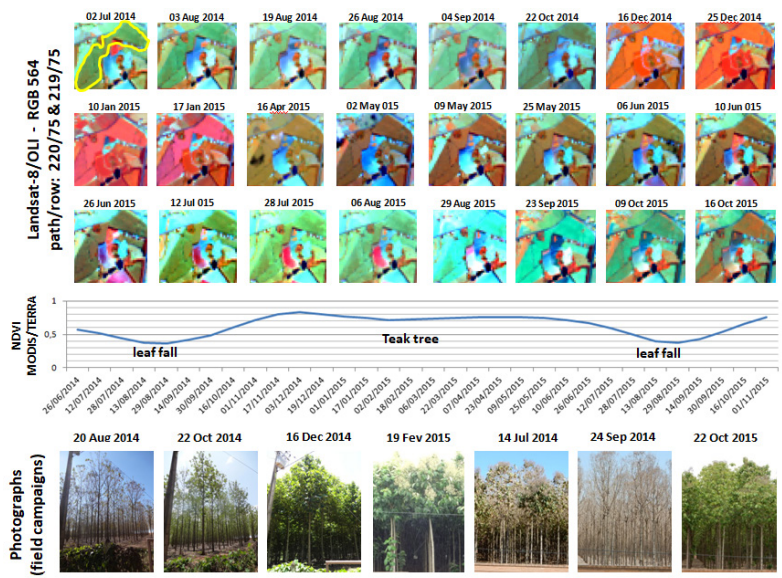
Figure 6. Field and satellite data of an area cultivated with teak tree. Source: Parts of the figure was adapted from Formaggio and Sanches (2017).

On the contrary, the teak tree showed spectral variation because of its deciduous characteristic (Figure 6). In OLI RGB564 composition, when the trees are leafless (in the plot analysed that occur from July until beginning of October), the image appears in green colour; after the growth of leaves, the image turns to red/brownish colours. In the NDVI profile, the values of the index greatly decrease during leaf fall.

It is interesting to mention that, comparing the MODIS/NDVI profiles of rubber tree (Figure 5) and teak tree (Figure 6), the drop in NDVI values during leaf fall is more severe for teak tree, and the period of leaf fall is greater for teak tree.

\section{DISCUSSION}

\subsection{Brazilian agriculture dynamics}

The area of the plots analysed varies between 8 and 400 hectares. According to the Brazilian Agricultural Census 2006, $27 \%$ of rural properties of SP, had less than 10 hectares and amounted to $2 \%$ of the total rural area of the state; $44 \%$ of them were between 10 and 500 ha and totalled $46 \%$ of the area in the state; while $30 \%$ of the properties had more than 500 ha in area and amounted to $52 \%$ of the total rural area.

Among the plots cultivated with annual crops, analysed, central pivot system irrigates fourteen of them and one receives water by gun irrigation. Irrigation, if properly used, is an efficient way to increase food production. According to the Brazilian Water Agency (ANA), irrigation is responsible for $72 \%$ of the water consumption in the Country. Brazil has 19.900 irrigating pivots covering an area of approximately 1.3 million hectares. This area is $43 \%$ bigger than was stated in the 2006 Brazilian agricultural census, demonstrating the increase of this irrigation system in the country. Around $80 \%$ of the area occupied by pivots in Brazil is concentrated in four states, and São Paulo is one of them with 14\% (ANA and EMBRAPA, 2016).

Brazil is one of the leading countries in the world in terms of adoption of the no-tillage system (Derpsch et al., 2010) and one of main reasons for this is that it permits the intensification of agriculture by using practices such as double cropping systems as a strategy to adapt crops to local climatic conditions (Arvor et al., 2014). There is a variety of types of crop rotation currently practiced in Brazil. The most common are the cropped areas with double cropping systems of soybean followed by maize, but there are other examples such as soybeans and cotton (Arvor et al., 2014). São Paulo was one of the first regions in Brazil adopting this practice in the post-1970 by the introduction of soy-wheat double cropping (Brannstrom and Oliveira, 2000). Recently, was reported the occurrence of double cropping such as soybean followed by soybean and maize after maize; beyond the traditional system of maize cultivated after soybean (Eberhardt et al., 2014).

Depending on market conditions, there are some producers who cultivate, in the same area, soybean as second crop (safrinha), in succession to soybeans in the first crop. This practice (soybean followed by soybean) presents phytosanitary problems. There may be a worsening of diseases, increasing attack by pests and greater difficulty in controlling the weeds. In addition, weather conditions during the period of the off- season (known as safrinha) are not ideal for obtaining high yields. These factors make soybean production in the offseason, although economically attractive in some scenarios, a high-risk activity for the producer.

In Brazil, the development of cultivars of increasingly shorter cycles fostered the expansion of plantations of maize as second crop in succession to soybeans, and the increase of other types of double cropping systems with summer crops, even in nonirrigated areas. In a publication of the main public institution of Brazilian agricultural research, from 1982, between the recommended maize genotypes for cultivation in the Cerrado region (Brazilian Savanna) there were only cultivars of late or semi-early cycles (EMBRAPA/CNPMS, 1982). More recently, for the 2013/2014 crop season, according to publication of the same company, there were 467 maize cultivars available in the seed market in Brazil, and over $90 \%$ of them were considered as cultivars of super-early and early cycles, $24 \%$ and $69 \%$, respectively (maize cycles not existing in 1982). According to Conab (2016), from 2013 the second crop of maize (safrinha) has been most prominent in the total production of this crop.

Among the seven plots of sugarcane monitored, only one was not harvest in 2015. This plot was last harvest in August 2014. In this region, there are two cycles for planting: "sugarcane of the year" and "year and a half sugarcane". In "sugarcane of the year", planting is performed between September and November, and the sugarcane is harvested after 12 months. In "year and a half sugarcane", planting is performed between January and April-May, and this cycle allows for harvest during the autumn season, after 18 months (Azania et al., 2013). Two of the stands analysed were burnt before harvest, which was easily detected in the OLI images (not shown). In early 1950s, sugarcane fields began to be harvested with pre-harvesting burning to increase the productivity of manual cutting what turned being required by introduction of mechanical shovels. After years, it was found that $74 \%$ of municipalities in the São Paulo state had the practice of pre-harvesting burning of sugarcane straw. In 2002, Law 11.241 was approved in SP, which provides for the gradual elimination of sugarcane straw burning until 2031, but in 2010 , more than $94 \%$ of the produced sugarcane already obeyed the law (Paraiso and Gouveia, 2015).

Cassava harvest occurred in January and October. Cassava (Manihot esculenta Crantz) is a shrub species native from Brazil, which grows continuously, with alternating plant growth periods and carbohydrate storage in its tuberous roots followed by periods of dormancy. Exploited as one of the main foodstuffs of the populations in the tropical regions, its storage roots are rich in starch. Although its ethnic and cultural values as food are strongly characterized in Brazil, cassava also is an important source of raw material for many industrialized agricultural products, especially in the states of São Paulo, Mato Grosso do Sul and Paraná and currently accounts for $64.7 \%$ of Brazilian starch production (Sagrilo et al., 2008). The harvest of cassava can occur after one or two cycles of cultivation, ranging from less than 10 to more than 20 months after planting depending on the time of planting and planted variety.

The only dynamic observed in the native forest plots was the burn of one of them. Rural landowners in Brazil are obliged to preserve natural areas on their properties. The Permanent Preservation Areas (APPs) and the so-called legal reserves are types of protected natural areas of a mandatory nature. Federal Legislation n. 12.651/2012 (amended by Law 12.727/2012) 
currently enforces them. The APPs are defined as areas located along watercourses, around water sources, steep slopes and in highlands (over 1,800 meters high). Legal reserves encompass a percentage of the area of a rural property where landowners have to maintain native vegetation. This percentage value will depend on the region and the biome where the rural property is located, and in São Paulo is equal to $20 \%$.

\subsection{Agricultural Remote Sensing}

All the factors described above have an impact on the use of remote sensing technology. The size of rural properties affects the type of sensor's spatial resolution that can be used. The agriculture intensification promoted by the use of artificial irrigation, no-tillage, diversity of species in crop rotation, variety of cycles of crops cultivars and double-cropping systems make the agricultural activity intensely dynamic, which demands sensors with high temporal resolution (one week or less) to acquire multitemporal data systematically.

Once multitemporal data with adequate spatial resolution is obtained, a set of valuable information about the agricultural activity can be extracted from it. For examples: crop management practices adopted such as no-tillage, crop rotation and burn before harvest; date of harvest; identify the type of production system used such as double-cropping and irrigation; and identify the period and homogeneity of leaf loss in deciduous plants. To be able to follow the entire plant phenological cycle, from sowing to harvest, can be used for mapping purposes, to estimate crop area, to monitor crops development, to evaluate crop condition, to monitor agriculture intensification, to do crop forecasting, for rural credit surveillance etc.

The success of using remote sensing will vary depending on the type of crop to be analysed. It is much more challenging to use optical remote sensing to map annual crops compared to semiperennial or perennial species. This is because of the short period that the annual crops last in the field (around 4 months). The situation is even worse for the annual crops cultivated during the raining season (more cloud cover). The example of soybean plot presented in Figure 2 exemplifies that difficulty; there were only tree images available (with reasonable cloud cover) during the entire development of the crop. This explain in part why Brazil had success in developing a method for sugarcane mapping, called CanaSat (Rudorff et al., 2010), but have not so far developed a robust methodology that could be applied operationally to map soybean, for example, national wide, using remote sensing.

Other difficulties to be faced when using remote sensing for agricultural applications in tropical areas are the variety of plant life cycles found and the different planting dates, even found in one single central pivot area. In addition, there is the issue of spectral behaviour similarity presented by different crops. For example, in OLI RGB564 compositions, soybean, bean and cassava plants in full vegetative development appears in yellow/orange colour in the images; while maize, sugarcane, wheat and potato appear in red/brown colour. Fortunately, there are ways of minimizing the problem. First of all, multitemporal data is crucial. Also, the combination of data from sensors of different spatial and temporal resolutions (e.g. OLI and MODIS) are very helpful. In addition, the knowledge about plants phenology and life cycles are fundamental (e.g., soybeans can be easily differentiated from cassava because it has a shorter cycle, likewise maize and sugarcane). In fact, the more information gathered about the target to be sensed, the greater the chances of success in using remote sensing.

As mentioned previously, from November to March there is a high intensity of agricultural land use in the study region. We can observe this all across the main agricultural areas in Brazil, since this is the most important Brazilian crop season (summer crops). The unavailability of OLI images in November and March, as reported in this study, hinders the identification of the period of planting and harvesting of firsts crops using remote sensing. However, for plant identification purposes, since there is a low diversity of annual crops cultivated in this period, the knowledge about the area (e.g. crops traditionally cultivated) can greatly help identifying the type of crop based on image analysis. Fortunately, for the months where a high variety of annual crops were found in the field (May to August), the chances of acquiring cloud free images is greater compared to summer (Erberhardt et al., 2016). This increases the chances of extracting information about plant phenological phases by remote sensing, and we can use this information to separate crops species.

As showed in this study, for the monitoring of tropical agriculture using remote sensing, two things are essential. First, it is necessary to have remote sensed data of high temporal resolution along all the development of the crops. Second, to have knowledge about the crops cultivated in the local to be monitored. The first issue is becoming less problematic with the increasing launch of new sensors and satellites, including passive and active sensors, constellations of satellites and nanosatellites. The second issue is more difficult to address, since field information is time-consuming and expensive to be acquired and demand specialists. However, researchers are becoming more willing to share their own data, and the number of free available databases containing field information are increasing, for example, the databases of Sanches et al. (2018a) and Sanches et al. (2018b).

\section{CONCLUSION}

The study area presented in this paper, that is representative of the agriculture of São Paulo state, Brazil, presents an intense variety in terms of cultivated species, type of cropping (single, double, triple), crop rotation used, duration of the crops phenological cycles and time of planting and harvesting. The regular and systematic monitoring of the same plots, conducted in this case study, allow us to better understand the intense dynamics of tropical agriculture. This understanding is fundamental to realize the importance of using multitemporal data of high temporal resolution (one week or less), all year around. Also, it shows the relevance of having knowledge about the crops traditionally cultivated and the agricultural practices in use, to be able to fully explore remote sensing for agricultural applications.

By associating the crop condition in the field and its appearance in multitemporal satellite images (RGB564 colour composition and NDVI profiles), it was possible to spectrally characterize the agricultural crops along their development. Several valuable information could be extracted from this analyse, such as crop specie identification, management practices adopted (e.g. crop rotation, no-tillage), date of harvest, identify the type o production system used (e.g. double-cropping, irrigation). 
With the improvement of the temporal resolution of Landsatlike sensors (e.g. Sentinel-2A and 2B), it would be possible to increase the chances of obtaining cloud free images. We have also to consider the combine use of passive data with SAR data, which are less affected by weather conditions. This will enable us to better explore the full potentiality of remote sensing technology in areas of intense dynamism, such the one described in this case study. This will boost the use of multitemporal analysis for diverse agricultural applications.

\section{ACKNOWLEDGEMENTS}

The authors acknowledge the Program "Science without borders" (Project 402.597/2012-5) of CNPq/CAPES for the financial support.

\section{REFERENCES}

ANA and EMBRAPA/CNPMS, 2016. Levantamento da agricultura irrigada por pivôs centrais no Brasil - ano 2014. http://metadados.ana.gov.br/geonetwork/ (8 June 2018) (In Portuguese).

Arvor, D., Dubreuil, V., Ronchail, J., Simões, M., Funatsu, B. M., 2014. Spatial patterns of rainfall regimes related to levels of double cropping agriculture systems in Mato Grosso (Brazil). International Journal of Climatology, 34, pp. 2622-2633, doi.org/10.1002/joc.3863.

Azania, M., Alberto, C., Rossini, L., Adriano, R. C., Perecin, D., Padua, A., 2013. The use of glyphosate in sugarcane: A Brazilian experience. In: A. J. Price and J. A. Kelton (Eds.), Herbicides - Current research and case studies in use. Croatia: InTech. Chapter 7, pp. 153-173, doi.org/10.5772/54958.

Brannstrom, C., Oliveira, A. M. S., 2000. Human modification of stream valleys in the western plateau of São Paulo, Brazil: implications for environmental narratives and management. Land Degradation \& Development, 11, pp. 535-548, doi.org/10.1002/1099-145X (200011/12)11:6<535::AIDLDR412>3.0.CO;2-L.

Companhia Nacional de Abastecimento - Conab, 2016. Acompanhamento da safra brasileira de grãos. Brasília: Conab, 3(4), pp. 149 (SAFRA 2015/16 - Quarto levantamento). http://www.conab.gov.br (11 May 2018) (In Portuguese).

Derpsch, R., Friedrich, T., Kassam, A., Hongwen, L., 2010. Current status of adoption of no-till farming in the world and some of its main benefits. International Journal of Agricultural and Biological Engineering, 3(1), pp. 1-25, doi.org/10.3965/j.issn.1934-6344.2010.01.001-025.

Eberhardt, I. D. R., Schultz, B., Rizzi, R., Sanches, I. D., Formaggio, A. R., Atzberger, C., Mello, M. P., Immitzer, M., Trabaquini, K., Foschiera, W., Luiz, A. J. B., 2016. Cloud cover assessment for operational crop monitoring systems in tropical areas. Remote Sensing, 8(3), pp. 219-232, doi.org/10.3390/rs8030219.

EMBRAPA/CNPMS - Empresa Brasileira de Pesquisa Agropecuária / Centro Nacional de Pesquisa de Milho e Sorgo, 1982. Recomendações técnicas para a cultura do milho. Sete Lagoas: Embrapa/CNPMS, 53 p. (Circular Técnica, 6). http://ainfo.cnptia.embrapa.br/digital/bitstream/item/37588/1/cir c-6-1.pdf (11 May 2018) (In Portuguese).

Formaggio, A.R. and Sanches, I.D., 2017. Sensoriamento Remoto em Agricultura. 1a ed. São Paulo: Oficina de Textos, pp. 285. (ISBN: 978-85-7975-277-3, eISBN: 978-85-7975-2827) (In Portuguese).

Paraiso, M. L. de S. and Gouveia, N., 2015. Health risks due to pre-harvesting sugarcane burning in São Paulo State, Brazil. Revista Brasileira de Epidemiologia, 18(3), pp. 691-701., doi.org/10.1590/1980-5497201500030014.

Rudorff, B. F. T., Aguiar, D. A., Silva, W. F., Sugawara, L. M., Adami, M., Moreira, M. A., 2010. Studies on the rapid expansion of sugarcane for ethanol production in São Paulo State (Brazil) using Landsat data. Remote Sensing, 2(4), pp. 1057-1076, doi.org/10.3390/rs2041057.

Sagrilo, E., Vidigal Filho, P. S., Pequeno, M. G., GonçalvesVidigal, M. C., Kvitschal, M. V., 2008. Dry matter production and distribution in three cassava (Manihot esculenta Crantz) cultivars during the second vegetative plant cycle. Brazilian Archives of Biology and Technology, 51(6), pp. 1079-1087, doi.org/10.1590/S1516-89132008000600001.

Sanches, I.D., Feitosa, R.Q., Diaz, P.M.A., Soares, M.D., Luiz, A.J.B., Schultz, B., Maurano, L.E.P., 2018a. Campo verde database: seeking to improve agricultural remote sensing of tropical areas. IEEE Geoscience and Remote Sensing Letters, 15(3), pp. 369-373, doi.org/10.1109/LGRS.2017.2789120.

Sanches, I.D., Feitosa, R.Q., Diaz, P.M.A., Montibeller, B., Luiz, A.J.B., Soares, M.D., Prudente, V.H.R., Vieira, D.C., Maurano, L.E.P., 2018b. The International Archives of the Photogrammetry, Remote Sensing and Spatial Information Sciences, XLII-1, pp. 387-393, doi.org/10.5194/isprs-archivesXLII-1-387-2018.

Sano, E.E., Ferreira, L.G., Asner, G.P., Steinke, E.T., 2007. Spatial and temporal probabilities of obtaining cloud-free Landsat images over the Brazilian tropical savanna. International Journal of Remote Sensing, 28(12), pp. 27392752, doi.org/10.1080/01431160600981517.

Schultz, B., 2016. Análise de imagens orientada a objetos e amostragem estatística no monitoramento de cana-de-açúcar, milho e soja no estado de São Paulo. PhD thesis in Remote Sensing - Instituto Nacional de Pesquisas Espaciais (INPE), São José dos Campos, São Paulo, Brasil, 2016. http://urlib.net/8JMKD3MGP3W34P/3L9BUQ5 (11 May 2018) (In Portuguese).

Whitcraft, A.K., Vermote, E.F., Becker-Reshef, I., Justive, C.O., 2015. Cloud cover throughout the agricultural growing season: impacts on passive optical earth observations. Remote Sensing of Environment, 156, pp. 438-447, doi.org/10.1016/j.rse.2014.10.009. 